\title{
PENGARUH MODEL PEMBELAJARAN KOOPERATIF DAN GAYA BERPIKIR TERHADAP HASIL BELAJAR QIRO'AH
}

\author{
Studi Eksperimen \\ Pada Mahasiswa Program Studi Pendidikan Agama Islam, Sekolah Tinggi Agama Islam Indoensia \\ (STAI INDO) 2017.
}

Khambali

Hambali.indramayu@gmail.com

\begin{abstract}
ABSTRAK
Penelitian ini bertujuan untuk menemukan pengaruh model pembelajaran dan gaya berpikir terhadap hasil belajar qiro'ah mahasiswa semester II tahun akademik 2016/2017. Prodi. Pendidikan Agama Islam, STAI Indonesia Jakarta.

Metode penelitian yang digunakan adalah metode eksperimen dengan desain ANOVA dua jalur pada taraf signifikansi 0,05 dan 0,01. Data dikumpulkan menggunakan dua instrumen yaitu tes membaca bahasa Arab dan angket gaya berpikir.

Temuan penelitian menyimpulkan bahwa hasil belajar qiro'ah pada penerapan pembelajaran koopeartif $M M$ lebih tinggi dibandingkan dengan pembelajaran kooperatif $N H T$, peserta didik dengan gaya berpikir divergen lebih tinggi dibandingkan dengan peserta didik dengan gaya berpikir konvergen, dan terjadi interkasi antara metode metode pembelajaran dan gaya berpikir terhadap hasil belajar qiro'ah.
\end{abstract}

Kata Kunci: Hasil belajar qiro'ah, pembelajaran kooperatif mind mapping, pembelajaran kooperatif numbered head together, gaya berpikir konvergen, gaya berpikir divergen.

\begin{abstract}
The objective of this research was to investigate comprehensively the effect of learning model and student's thinking style on the Arabic reading achievement of the second semester student of the Islamic Studies Program, the Institut of Islamic Studies of Indonesia Jakarta, academic year 2016/2017.

This was an experimental research using a two-factor ANOVA at 0,05 and 0,01 significance level. The data was collected using the Arabic reading test and thinking style questionaire.

The findings above led to a conclusion that the result of arabic reading in cooperatif of MM was higher than cooperatif of NHT, Students who has divergen thinking style was higher than student who has covergent thinking, and its happened an interaction between cooperatif model teaching and thinking style to the result of arabic reading.
\end{abstract}

Key words: Arabic reading achievement, cooperative learning of mind mapping, cooperative learning of numbered head together, divergent thinking, convergent thinking. 


\section{Pendahuluan}

Bahasa Asing khususnya bahasa Arab sangat penting dalam kehidupan bermasyarakat di Indonesia karena sejak dulu bangsa Indonesia memiliki hubungan yang erat dengan bangsa Arab khususnya di bidang keagamaan. Berkenaan dengan itu maka belajar bahasa Arab melalui qiro'ah (membaca) menjadi sangat penting karena dengan qiro'ah kita dapat mengembangkan wawasan lebih dalam mengenai kebudayaaan, sosial politik, dan khususnya keagamaan (Al-ubdaidi, 2011:8). Sebagaimana definisi membaca yaitu proses mendapatkan pesan dari tulisan (Nuttal, 1989:3), dengan demikian pembelajaran qiro'ah (membaca) bahasa Arab perlu dirancang model pembelajaran yang baik agar kegiatan pembelajaran menjadi efektif dan efesien.

Namun sayangnya perkembangan peran bahasa Arab di Indonesia masih sebagai alat atau perantara untuk memahami ilmu agama saja (Jurnal Pendidikan Agama Islam dan Kebahasaaraban, 3, (1), 2016, 32-51, h. 34) sehingga mayoritas model pengajarannya masih bertolak pada model tradisional yaitu metode gramatika dan terjemah (Delami, h. 40), sebagaimana diketahui bahwa model pengajaran tradisional hanya bertumpu pada inisiasi, respon, dan umpan balik/evaluasi (Wendy Jolliffe, 2007, h. 3) tanpa mempertimbangkan kognisi, padahal dewasa ini telah ditemukan banyak model pembelajaran yang lebih baik dan telah teruji secara empirik. 
Dewasa ini rancangan pembelajaran menuntut peserta didik agar lebih aktif dibandingkan pendidik dalam kegiatan pembelajaran (Abidin, 2013:12). Karakteristik pembelajaran seperti itu di antaranya adalah pembelajaran yang menggunakan pendekatan kontruktivis (Slavin, 2009:10) yang diwujudkan dengan model kooperatif. Model pembelajaran kooperatif tidak hanya menuntut peserta didik untuk saling mendukung satu sama lain dalam tim dari sisi kognitif saja tetapi lebih dari itu yaitu tanggung jawab, kepedulian sosial, pengembangan kreatifitas dan lain-lain (Asmani, 2016: 57; Kagan \& Kagan, 2009:41; Jollifie, 2007:46; Crowford, 2005:48).

Model pembelajaran kooperatif banyak jenisnya (Slavin, 2009:22), hal ini karena metode pembelajarannya dapat aplikasikan dalam kelas secara fleksibel. Ragam model kooperatif yang penulis anggap cocok untuk diaplikasikan dalam pembelajaran membaca bahasa Arab untuk level pemula atau level memahami adalah model kooperatif teknik mind mapping (di dingkat kooperatif $M M$ ) dan teknik numbered head together (disingkat kooperatif $N H T$ ). Pembelajaran kooperatif $M M$ adalah metode pembelajaran kerja sama membangun sebuah konstruk berupa mind mapping yang memanfaatkan otak peserta secara menyeluruh dengan menggunakan citra visual (gambar) dan prasarana grafis lainnya sehingga membentuk kesan (Swadarma, 2012:8). Dengan demikian pembelajar pemula diharapkan dapat bersama-sama mengingat berbagai kosa kata baru dan memahaminya dengan cepat. Sedangkan pembelajaran kooperatif numbered head together metode ini memberikan kesempatan kepada setiap peserta didik untuk 
saling membagikan ide-ide agar mendapatkan pilihan atau solusi yang paling tepat (Lie, 2010:59).

Perencanaan pembelajaran lainnya yang perlu diperhatikan adalah memahami kondisi kepribadian peserta didik, karena mereka memiliki kepribadian yang beragam, oleh karena itu maka mereka juga mempunyai keragaman pada gaya berpikir. Gaya berpikir adalah cabang psikologi yang mengkaji tentang cara yang disukai individu dalam menggunakan kemampuan atau ketrampilan yang dimilikinya untuk mengatasi masalah yang dihadapinya (Sterenberg, 2009:8, Santrock, 2015:155, Al-utum, 2007:34). Kemampuan atau perilaku tersebut merupakan manifestasi dari kognitif (Solso, 2005:418-419). Gaya berpikir terbagi atas dua macam, yaitu gaya berpikir divergen dan gaya berpikir konvergen. Perserta didik dengan dominasi gaya berpikir divergen memiliki keunggulan dalam: 1) kelancaran, 2) fleksibilitas, dan 3) orisinalitas, mereka berpikir tidak hanya pada satu konteks tertentu saja namun melibatkan yang lain (Lehay, 2012:273). Dengan demikian mereka dapat berpikir bebas dan bahkan mampu memproduksi ide. Adapun perserta didik dengan dominasi gaya berpikir konvergen memiliki keunggulan dalam hal ketepatan pemilihan kuantitas, karena selalu berpikir logis dan konvensional (Lehay, 2012:273).

Berdasarkan uraian di atas, proses pembelajaran membaca bahasa Arab yang dilakukan dengan model pembelajaran kooperatif yang kepribadian gaya berpikir peserta didiknya telah analisis terlebih dahulu, maka diharapkan dapat dapat meningkatkan hasil belajar membaca bahasa Arab. 


\section{PEMBAHASAN}

\section{Hasil Belajar Membaca Bahasa Arab}

Hasil belajar merupakan perubahan perilaku siswa akibat belajar. Perubahan itu diupayakan dalam proses belajar mengajar untuk mencapai tujuan pendidikan. Perubahan perilaku individu akibat proses belajar tidaklah tunggal. Setiap proses belajar mempengaruhi perubahan perilaku pada domain tertentu pada diri siswa, tergantung perubahan yang diinginkan sesuai dengan tujuan pendidikan (Purwanto, 2011, h. 34). Benjamin S. Bloom menyebutkan bahwa terdapat tiga ranah hasil belajar, yaitu kognitif, afektif, dan psikomotorik (Asep Jihad dan Abdul Haris, 2012, h. 45).

Berdasarkan pada taksonomi Bloom, setiap ranah tersebut masih perlu diperinci lagi. Pada bagian ini peneliti hanya berfokus pada perubahan kognitif. Adapun perubahan kognitif diuraikan menjadi: 1) Pengetahuan merupakan tingkatan yang secara operasional diartikan sebagai memanggil kembali (retrieval). 2) Pemahaman meliputi: terjemah, interpretasi, extrapolaton (ramalan). 3) Aplikasi diartikan siswa dapat mendemonstrasikan penggunaan materi jika dia diminta melakukannya. 4) analisis, dibagi tiga yaitu: elemen-elemen, keterkaitan antar elemen, dan dasar-dasar organisasi yang membangun elemen. Level ini nampaknya agak tumpang tindih dengan pemahaman dan evaluasi. 5) Sintesis yaitu meletakan elemen-elemen dan bagian-bagian secara bersama-sama dalam kesatuan yang utuh. 6) evaluasi adalah membuat keputusan tentang nilai pengetahuan (Robert J. Marzano dan John S. Kendall, 2007, h. 5-8). 
Sedangkan membaca adalah adalah mengenali dan memahami isi sesuatu yang terulis (lambang-lambang tertulis) dengan melafalkan atau mencernanya di dalam hati (Asep Hermawan, 2014, h. 143). Membaca dalam pengertian sempit adalah kegiatan memahami makna yang terdapat dalam tulisan. Dalam pengertian luas, membaca adalah proses pengolahan bacaan secara kritis-kreatif yang dilakukan pembaca untuk memperoleh pemahaman menyeluruh tentang bacaan itu, yang diikuti oleh penilaian terhadap keadaan, nilai, fungsi, dan dampak bacaan itu (Nurhadi, 2016, h. 2).

\section{Penilaian (assessment) Membaca Bahasa Arab}

Dalam rangka mengetahui hasil belajar membaca maka harus dilakukan penilaian atau asesmen (Sri wahyuni dan Abd. Syukur Ibrahim, 2012, h. 1). Penilain atau assesment adalah proses mendapatkan informasi (Lisa Bohlin, Cheyl Cisero Durwin, dan Marla Reese Webe, 2012, h. 277). Dalam penilaian atau asesmen diperlukan alat untuk mengukur kemampuan peserta didik, alat ukur hasil belajar di antaranya dengan tes dan nontes.

Tes adalah suatu cara untuk mengadakan evaluasi yang berbentuk tugas atau serangkaian tugas yang harus dikerjakan oleh peserta tes sehingga menghasilkan skor tentang prestasi atau tingkah laku peserta tes, yang dibandingkan dengan nilai standar tertentu yang telah ditetapkan (Sri wahyuni dan Abd. Syukur Ibrahim, 2012, h. 10). Sedangkan nontes adalah suatu cara yang digunakan untuk mengukur kompetensi secara mandiri dan dapat pula digunakan sebagai pelengkap alat lain 
dalam rangka mengungkapkan: ketrampilan, kebiasaan-kebiasaan belajar, sikap, minat, motivasi, apresiasi, ataupun penyesuaian (Sri wahyuni dan Abd. Syukur Ibrahim, 2012, h. 10).

Sedangkan tes dilihat dari cara menajawabnya, dibedakan atas tes objektif, dan non objektif. Nilai objektif merujuk pada tingkatan yang mana dua evaluator atau lebih setuju pada nilai atau skor performa siswa. Jenis-jenis tes objektif adalah: pilihan ganda, benar/salah, dan menjodohkan lebih mudah dinilai daripada jenis menjawab pendek dan essay Lisa Bohlin, Cheyl Cisero Durwin, dan Marla Reese Webe, 2012, h. 494). Sedangkan tes non objektif adalah tes yang cara menjawabnya dengan menyebutkan dan menjelaskan berupa uraian tentang hal-hal yang sudah dipelajari. Yang termasuk tes bahasa non objektif adalah: 1) isian (melengkapi), 2) jawaban singkat, 3) soal uraian (Sri wahyuni dan Abd. Syukur Ibrahim, 2012, h. 12).

Khusus dalam asesmen membaca, tes diklasifikasikan kepada: 1) membaca literal yaitu terdiri atas pengetahuan dan pemahaman, 2) membaca interpretatif yaitu berupa terapan, 3) membaca kreatif/kritis yaitu berupa analisis, sintesis, dan evaluasi (Sri wahyuni dan Abd. Syukur Ibrahim, 2012, h. 34).

Dalam menyusun penilaian membaca untuk pemula kategori tes yang disusun fokus pada aspek formal bahasa yaitu leksikal, gramatikal, dan sedikit karakteristik wacana. Jenis-jenis tes yang bisa digunakan untuk menilai leksikal dan gramatikal pada aspek membaca adalah: 1) pilihan ganda, 2) mencocokan, 3) mengedit, 4) gap filling. Jenis tes yang paling spopuler digunakan dalam tes membaca pengetahuan kosa kata dan 
tata bahasa (H. Douglas Brown, h. 194-200) dan pemahaman teks (Christine Nutal, 1998, h. 223) adalah dengan format pilihan ganda, karena format ini mudah untuk dilakukan administrasi dan bisa membuat skor dengan cepat (Christine Nutal, 1998, h. 223).

\section{Metode Penelitian}

Penelitian ini dilaksanakan pada peserta didik semester II di program studi Pendidikan Agama Islam, Sekolah Tinggi Agama Islam Indonesia (STAI INDO) Jakarta, tahun akademik 2016/2017. Model penelitian yang digunakan adalah model eksperimen, di mana pada kelas eksperimen diterapkan model pembelajaran kooperatif mind mapping (MM) dan pada kelas kontrol diterapkan model pembelajaran kooperatif numbered head together (NHT). Adapun desain yang digunakan adalah desain faktorial $2 \times 2$.

\begin{tabular}{|c|c|c|}
\hline \multirow{2}{*}{ Gaya Berfikir (B) } & \multicolumn{2}{|c|}{ Pemebelajaran Kooperatif (A) } \\
\cline { 2 - 3 } & Mind Mapping (A1) & NHT (A2) \\
\hline Gaya Berfikir Konvergen (B1) & (A1), (B1) & (A2), (B1) \\
\hline Gaya Berfikir Divergen (B2) & (A1), (B2) & (A2), (B2) \\
\hline
\end{tabular}

Tabel desain faktorial $2 \times 2$

Teknik yang digunakan untuk mengumpulkan data dalam penelitian ini adalah dengan menggunakan dua instrumen, yaitu: (1) tes qiro'ah (membaca) bahasa Arab, dan (2) tes gaya berpikir. Pengujian validitas tes qiro'ah (membaca) bahasa Arab didasarkan pada uji validitas teoritik oleh ahli dan juga pada uji validitas tes secara empirik kepada 45 mahasiswa dan dihitung dengan menggunakan rumus point 
biserieal. Dari penghitungan itu diperoleh 38 butir tes valid. Sedangkan untuk melihat reliabilitasnya, dilakukan penghitungan reliabilitas tes dengan rumus KR 20 dan KR 21. Dari hasil analisis reliabilitas diperoleh nilai koefisiensi 0,736 . Tingkat reliabilitas ini termasuk kategori tinggi. Untuk mengetahui validitas instrumen gaya berpikir yang berupa angket sebanyak 61 butir pernyataan, didasarkan pada validitas teoritik dan expert judgement. Sedangkan untuk mengetahui reliabilitasnya, digunakan penghitungan dengan rumus alpha cronbach. Berdasarkan hasil analisis butir instrumen diperoleh koefisien reliabilitas 0,812 . Hal ini berarti bahwa data yang memiliki reliabilitas dengan kategori baik.

Sebelum data dianalisis, terlebih dahulu dilakukan uji prasyarat yang meliputi uji normalitas dan uji homogenitas. Uji normalitas dilakukan dengan menggunakan uji Liliefors, sedangkan uji homogenitas dilakukan dengan menggunakan uji Bartlett pada taraf signifikansi $a=0,05$.

\begin{tabular}{|c|c|c|c|c|c|}
\hline No & Kelompok & $\mathbf{N}$ & $\mathbf{L}_{\mathbf{h i t}}$ & $\mathbf{L}_{\text {tab }}$ & Keterangan \\
\hline 1. & $\mathrm{~A}_{1}$ & 24 & 0,10 & 0,19 & Normal \\
\hline 2. & $\mathrm{~A}_{2}$ & 21 & 0,14 & 0,19 & Normal \\
\hline 3. & $\mathrm{~B}_{1}$ & 23 & 0,07 & 0,19 & Nomral \\
\hline 4. & $\mathrm{~B}_{2}$ & 22 & 0,14 & 0,19 & Normal \\
\hline 5. & $\mathrm{~A}_{1} \mathrm{~B}_{1}$ & 12 & 0,108 & 0,242 & Normal \\
\hline 6. & $\mathrm{~A}_{1} \mathrm{~B}_{2}$ & 12 & 0,129 & 0,242 & Normal \\
\hline 7. & $\mathrm{~A}_{2} \mathrm{~B}_{1}$ & 11 & 0,119 & 0,249 & Normal \\
\hline 8. & $\mathrm{~A}_{2} \mathrm{~B}_{2}$ & 10 & 0,256 & 0,258 & Normal \\
\hline
\end{tabular}

Tabel uji normalitas data

\begin{tabular}{|c|c|c|c|c|c|}
\hline No. & Kelompok & Db & $\chi_{\text {hitung }}^{2}$ & $\chi_{\text {tabel }}^{2}$ & Kesimpulan \\
\hline 1. & $\mathrm{~A}_{1} \mathrm{~B}_{1}, \mathrm{~A}_{1} \mathrm{~B}_{2}, \mathrm{~A}_{2} \mathrm{~B}_{1}, \mathrm{~A}_{2} \mathrm{~B}_{2}$ & 3 & 0,34 & 7,81 & Homogen \\
\hline
\end{tabular}




\begin{tabular}{|c|c|c|c|c|c|}
\hline 2. & $\mathrm{~A}_{1}$ dan $\mathrm{A}_{2}$ & 1 & 0,431 & 3,84 & Homogen \\
\hline 3. & $\mathrm{~B}_{1}$ dan $\mathrm{B}_{2}$ & 1 & 0,829 & 3,84 & Homogen \\
\hline
\end{tabular}

Tabel uji homogenitas data

Uji Liliefors dan uji Bartlett menunjukkan bahwa keseluruhan data penelitian berdistribusi normal dan homogen. Untuk itu analisis dilanjutkan dengan pengujian analisis varians (ANOVA).

Analisa data pada penelitan ini dilakukan dengan teknik ANOVA (analysis of variance) pada taraf signifikansi $\mathrm{a}=0,05$ dan $\mathrm{a}=0,01$. Apabila di dalam analsis ditemukan interaksi, maka dilanjutkan dengan uji Tukey.

\begin{tabular}{|c|c|c|c|c|c|c|}
\hline \multirow{2}{*}{ Gaya berpikir } & \multicolumn{4}{|c|}{ Metode Pembelajaran } & \multirow{2}{*}{\multicolumn{2}{|c|}{ Jumlah Baris }} \\
\hline & \multicolumn{2}{|c|}{ MM } & \multicolumn{2}{|c|}{ NHT } & & \\
\hline \multirow{4}{*}{ Konvergen } & $\mathrm{n}=$ & 12 & $\mathrm{n}=$ & 11 & $\mathrm{n}=$ & $=23$ \\
\hline & $\sum x_{11}=$ & 249 & $\sum x_{21}=$ & 258 & $\sum X_{B 1}$ & $=507$ \\
\hline & $\sum x_{11}^{2}=$ & 5335 & $\sum x_{21}^{2}=$ & 6246 & $\sum \mathrm{X}_{\mathrm{B} 1}^{2}$ & $=11581$ \\
\hline & $\overline{\mathrm{X}}_{11}=$ & 20,75 & $\overline{\mathrm{X}}_{21}=$ & 23,45 & $\overline{\mathrm{X}}_{\mathrm{B} 1}$ & $=22,04$ \\
\hline \multirow{4}{*}{ Difergen } & $\mathrm{n}=$ & 12 & $\mathrm{n}=$ & 10 & $\mathrm{n}=$ & 22 \\
\hline & $\sum x_{12}=$ & 355 & $\sum x_{22}=$ & 196 & $\sum \mathrm{x}_{\mathrm{B} 2}$ & $=551$ \\
\hline & $\sum x_{12}^{2}=$ & 10721 & $\sum X_{22}^{2}=$ & 4036 & $\sum \mathrm{X}_{\mathrm{B} 2}^{2}$ & $=14757$ \\
\hline & $\overline{\mathrm{X}}_{12}=$ & 29,58 & $\bar{X}_{22}$ & 19,60 & $\overline{\mathrm{X}}_{\mathrm{B} 2}$ & $=25,05$ \\
\hline \multirow{4}{*}{ Jumlah } & $\mathrm{n}=$ & 24 & $\mathrm{n}=$ & 21 & $\mathrm{n}=$ & $=45$ \\
\hline & $\sum \mathrm{x}_{\mathrm{A} 1}=$ & 604 & $\sum \mathrm{x}_{\mathrm{A} 2}=$ & 454 & $\sum \mathrm{X}_{\text {Total }}$ & $=1058$ \\
\hline & $\sum X_{\mathrm{A} 1}^{2}=$ & 16056 & $\sum X_{\mathrm{A} 2}^{2}=$ & 10282 & $\sum X_{\text {Total }}^{2}$ & $=26338$ \\
\hline & $\overline{\mathrm{X}}_{\mathrm{A} 1}=$ & 25,17 & $\overline{\mathrm{X}}_{\mathrm{A} 2}=$ & 21,62 & $\overline{\mathrm{X}}_{\text {Total }}$ & $=23,39$ \\
\hline
\end{tabular}

Tabel analisis varians (ANOVA) 


\begin{tabular}{|l|c|c|c|c|c|c|}
\hline \multicolumn{1}{|c|}{$\begin{array}{c}\text { Sumber } \\
\text { Varians }\end{array}$} & db & \multirow{2}{*}{ JK } & \multirow{2}{*}{ MK } & \multirow{2}{*}{ Fhitung } & \multicolumn{2}{c|}{ Ftabel } \\
\cline { 6 - 8 } & & & & & $\alpha=0,05$ & $\alpha=0,01$ \\
\hline Antarkolom (A) & 1 & 140,959 & 140,96 & 7,44 & 4,11 & 7,40 \\
\hline Antarbaris (B) & 1 & 101,3334 & 101,33 & 5,35 & 4,11 & 7,40 \\
\hline Interaksi (AB) & 1 & 444,6584 & 444,66 & 23,48 & 4,11 & 7,40 \\
\hline Dalam & 41 & $\mathbf{7 7 6 , 2 9 3 9}$ & 18,93 & & & \\
\hline Total & 44 & & & & & \\
\hline
\end{tabular}

Tabel kesimpulan hasil analisis varians (ANOVA)

Pada tabel di atas menunjukkan bahwa ditemukan pengaruh interaksi antara antara model pembelajaran kooperatif dengan gaya berpikir terhadap hasil belajar membaca bahasa Arab peserta didik. Oleh karena itu penghitungan dilanjutkan dengan uji Tukey.

\begin{tabular}{|c|c|c|c|c|c|}
\hline \multirow{2}{*}{ Kelompok Data } & \multirow{2}{*}{$\mathrm{N}$} & \multirow{2}{*}{$\mathbf{Q}_{\text {hitung }}$} & \multicolumn{2}{|c|}{$\mathbf{Q}_{\text {tabel }}$} & \multirow{2}{*}{ Keterangan } \\
\cline { 4 - 5 } & & & $\alpha=0,05$ & $\alpha=0,01$ & \\
\hline $\mathrm{A}_{1 \text { dan }} \mathrm{A}_{2}$ & 24 & 4,00 & 2,92 & 3,96 & Sangat Signifikan \\
\hline $\mathrm{B}_{2 \text { dan }} \mathrm{B}_{1}$ & 23 & 3,34 & 2,95 & 4,02 & Signifikan \\
\hline $\mathrm{A}_{2} \mathrm{~B}_{1}$ dan $\mathrm{A}_{1} \mathrm{~B}_{1}$ & 12 & 2,16 & 3,08 & 4,32 & Tidak Signifikan \\
\hline $\mathrm{A}_{1} \mathrm{~B}_{2}$ dan $\mathrm{A}_{2} \mathrm{~B}_{2}$ & 12 & 7,95 & 3,08 & 4,32 & Sangat Signifikan \\
\hline
\end{tabular}

Tabel kesimpulan hasil uji Tukey

Berdasarkan pada tabel kesimpulan analisis varians (ANOVA) dan uji Tukey di atas, maka analisis hipotesisnya adalah sebagai beirkut:

\section{Temuan Penelitian}

Hipotesis pertama. Hasil belajar membaca bahasa Arab peserta didik yang belajar dengan model pembelajaran kooperatif teknik Mind Mapping lebih tinggi dari pada peserta didik yang belajar dengan model pembelajaran 
kooperatif teknik Numbered Head Together (NHT). Analisis ini menggunakan uji ANOVA dan uji Tukey. Hasil penghitungan ANOVA menunjukkan bahwa $F_{\text {hitung }}(A)=$ 7, $44>\mathrm{F}_{\text {tabel }}$, baik pada taraf signifikansi $\alpha=0,05$ maupun $\alpha=0,01$ dan $\mathrm{Q}_{\text {hitung }}=$ $4,00>Q_{\text {tabel }}$. baik pada taraf signifikansi $\alpha=0,05$ maupun $\alpha=0,01$. Hal ini berarti bahwa $\mathrm{H}_{\mathrm{o}}$ ditolak dan $\mathrm{H}_{1}$ diterima. Dengan kata lain, dapat disimpulkan bahwa hasil belajar qiro’ah (membaca) bahasa Arab perserta didik yang belajar dengan model pembelajaran kooperatif (MM) lebih tinggi dibandingkan dengan perserta didik yang belajar dengan model pembelajaran kooperatif $N H T$.

Berdasarkan penelitian yang dilakukan selama masing-masing delapan kali pertemuan di kelas $M M$ dan kelas $N H T$, peneliti menemukan bahwa meskipun $M M$ dan NHT merupakan bagian dari rumpun pembelajaran kooperatif tapi tampaknya kooperatif $M M$ memiliki keungulan dan karakteristik yang lebih baik.

Seperti dijelaskan bahwa pembelajaran kooperatif adalah pembelajaran dengan bantuan teman yang mengoptimalkan seluruh aspek pembelajaran baik itu kognitif, psikomotorik, maupun afektif. Ketika pembelajaran kooperatif dipadu dengan teknik MM di mana pembelajaran membaca di arahkan untuk saling membantu memahami materi, lalu pemahaman itu diejawantahkan pada sebuah projek mind mapping yang dibuat semenarik mungkin dengan pola-pola garis dan warna pada selembar kertas A4. Kegiatan pembelajaran seperti itu ternyata tidak hanya dapat membantu peserta didik mengingat kosa kata baru dengan kuat, tetapi juga mereka dapat mengaitkan setiap kata dengan kata lain yang saling berhubungan sehingga 
dapat membentuk suatu kalimat. Pada dasarnya, memang, setiap kalimat yang tertuang pada teks akan menjadi lebih sederhana dan praktis ketika diletakkan pada sebuah mind mapping, karena pada mind mapping dapat mengaitkan tidak hanya antar kata bahkan antar kata dan kalimat, dan kalimat dengan kalimat.

Berikut ini beberapa unsur pembelajaran kooperatif $M M$ yang membantu peserta didik dapat membaca dengan baik, yaitu: 1) Cara berpikir peserta didik menjadi terpusat karena fokus pembahasan materi dilukiskan pada sebuah gambar bersar yang diletakkan di tengah, 2) dari pusat itu yang menjadi pembahasan/kegiatan teks dicari bersama-sama lalu hasilnya dilukiskan menjadi cabang-cabang yang berwarna dari pusat itu , 3) cabang-cabang itu dilanjutkan dengan mancatat apa saja yang masih terkait, 4) setiap cabang ataupun cabang berikutnya adalah kata kunci, 5) peserta didik menggambar pada kata kunci jika kata kunci itu dapat mereka ilustrasikan menjadi sebuah gambar.

Unsur-unsur tersebut tidak ada dalam kooperatif NHT. Tampaknya unsurunsur yang terjadi pada koopertaif $M M$ memberikan pengaruh yang signifikan terhadap hasil belajar qiro'ah (membaca) bahasa Arab perserta didik. Ada beberapa hal yang dapat membuktikan keberadaan/ketiadaan unsur-unsur tersebut dalam kelas kooperatif $M M$ dan kooperatif $N H T$.

Pertama, membaca merupakan aktifitas kognitif yang menuntut kerja otak secara optimal dalam memahami teks, selaras dengan aktifitas tersebut, cara-cara kerja mind mapping pun demikian yaitu mengoptimalkan kerja otak secara maksimal 
dengan melibatkan otak kanan dan kiri secara sinergis ketika mengolah berbagai informasi termasuk juga ketika merangkum teks yang dituangkan ke dalam mind mapping yang berupa garis-garis, warna-warni, dan paduan gambar yang menarik, mereka saling berdiskusi bagaimana menentukan kata-kata dari teks untuk dicatat pada setiap cabang yang selaras dengan pusat mind mapp lalu mewarnainya dan jika perlu diberi gambar sehingga ini dapat membantu perserta didik dalam memahami teks dengan cepat dan mengingatnya dengan kuat. Sedangkan pada kooperatif $N H T$, kegiatan berpikir peserta didik berdasar pada pijakan buku dan diskusi dengan teman-teman kelompok, oleh karena itu cara-cara ini tampaknya kurang begitu berkesan dengan kuat dalam menghafal kosa kata baru dan memahami teks.

Kedua, atribut atau media. Pada kelas kooperatif $M M$ atribut yang digunakan dalam rangka memahami materi adalah berupa kertas polos A4 dan spidol berwarna. Atribut tersebut digunakan untuk merangkum teks secara sistematis dan terstruktur dari topik utama (titik tengah) sampai ke keterangan yang terperinci (cabang-cabang) atas pemahaman mereka sendiri dalam kelompok. Rangkuman tersebut tidak hanya dicatat tetapi juga (bila perlu) digambar dan diberi warna sehingga dapat menarik dilihat dan mudah dipahami dengan cepat. Sedangkan atribut pada kooperatif $N H T$ adalah nomor kartu pada tiap-tiap peserta didik, atribut itu berfungsi hanya untuk memberi tanda konfirmasi. Atribut yang ada pada kelas kooperatif $M M$ tampaknya sangat efektif digunakan di kelas dibandingkan dengan atribut pada kelas NHT.

Ketiga, proses belajar. Pada kooperatif $M M$, kegiatan pembelajran melalui diskusi dan membuat mind mapping, kegiatan ini terletak pada kegiatan proses atau 
elaborasi, perserta didik tidak sekedar berdiskusi dalam memahami materi tetapi hasil diskusi mereka dicatat pada mind mapping. Berbeda dengan kooperatif $N H T$ yaitu kegiatan utamanya terletak pada kegiatan konfirmasi bukan pada elaborasi.

Keempat, fokus kegiatan. Pada kelas kooperatif $M M$, proses elaborasi materi ajar lebih menekankan pada kegiatan meringkas dan membuat rancangan bersama. Perserta didik saling bekerja sama membangun mind mapping yang baik yakni yang menarik, mudah dipahami dan padat informasi, sedangkan kooperatif NHT fokus kegiatan tertuju pada kegiatan tanya jawab dan games.

Perbedaan-perbedaan antara pembelajaran yang terjadi di dalam kelas kooperatif $M M$ dan yang terjadi di dalam kelas kooperatif $N H T$ sebagaimana telah diuraikan di atas, ternyata berpengaruh secara signifikan terhadap hasil belajar qiro'ah (membaca) bahasa Arab perserta didik. Dengan kata lain, perbedaanperbedaan antara pembelajaran yang terjadi di dalam kelas kooperatif $M M$ dan yang terjadi di dalam kelas kooperatif $N H T$ telah membuat hasil belajar qiro'ah (membaca) bahasa Arab perserta didik yang belajar dengan model kooperatif $M M \underline{\text { lebih baik }}$ dibandingkan dengan perserta didik yang belajar dengan model kooperatif $N H T$.

Hipotesis Kedua. Hasil belajar membaca bahasa Arab peserta didik yang memiliki kecenderungan gaya berpikir divergen lebih tinggi dari pada peserta didik yang memiliki gaya berpikir konvergen. Analisis ini menggunakan uji ANOVA dan uji Tukey. Hasil penghitungan ANOVA menunjukkan bahwa $F_{\text {hitung }}(B)=5,35>$ $\mathrm{F}_{\text {tabel, }}$, pada taraf signifikansi $\alpha=0,05$. Hasil penghitungan uji Tukey pun 
menunjukkan hal yang sama yaitu $Q_{\text {hitung }}=3,34>Q_{\text {tabel }}$ pada taraf signifikansi $\alpha=$ 0,05, maka $\mathrm{H}_{0}$ ditolak dan $\mathrm{H}_{1}$ diterima. Dengan kata lain, hasil belajar qiro'ah (membaca) bahasa Arab perserta didik yang memiliki kecenderungan gaya berpikir divergen lebih tinggi dibandingkan dengan perserta didik yang memiliki kecenderungan gaya berpikir konvergen.

Ketika penelitian ini berlangsung, peneliti mengamati perilaku peserta didik yang memiliki kecenderungan gaya berpikir divergen (disingkat perserta didik divergen) dan peserta didik yang memiliki kecenderungan gaya berpikir konvergen (di singkat peserta didik konvergen). Sama seperti pemaparan di atas, peneliti melihat perserta didik divergen memiliki keunggulan dalam: 1) kelancaran dalam berpikir, 2) mampu berpikir fleksibel, dan 3) hasil permikirannya orisinil atau kreatif.

Dalam kegiatan membaca, terlebih membaca bahasa Arab tingkat pemula, seringkali menemui kosa-kata baru atau kosa kata yang akrab namun pada konteks kalimat yang baru sehingga sulit dicerna dan dipahami, hal ini sangat maklum, namun untuk peserta didik divergen mereka terus mencoba dari berbagai sisi agar dapat memahaminya, yakni memahami kata atau kalimat yang sulit dapat dilakuan dengan berbagai cara, seperti mencari turunan kata atau derivasinya, melihat konteks tema, melihat susunan kata sebelum dan sesudahnya, bertanya ke teman, mencari di kamus, dan bertanya kepada instruktur. Mereka berpikir tidak hanya pada satu konteks tertentu saja namun melibatkan unsur lain sehingga selalu ada upaya agar tidak menemui kebuntuan ide. Dengan demikian mereka dapat berpikir bebas dan bahkan mampu berkreasi positif untuk kemajuan pembelajarannya, sehingga tidak 
hanya kesulitan cepat teratasi namun mendapatkan sesuatu yang baru dan bermanfaat yang masih berkaitan dengan materi utama.

Adapun perserta didik konvergen seperti yang peneliti amani, mereka memiliki keunggulan dalam hal ketepatan pemilihan kuantitas, mereka nampaknya selalu berpikir logis dan konvensional, mereka cenderung pada hafalan dan teksbook saja, jika mereka menemukan kata atau kalimat yang sulit kecenderungan mereka selalu pada kamus, namun sayangnya terkadang makna yang tersedia pada kamus tidak selamanya akurat karena konteks makna yang diminta pada teks terkadang berlainan dengan solusi yang diberikan oleh kamus, mereka juga cenderung sulit menerima jika solusi yang diberikan oleh temannya berbeda dengan pengalamannya, mereka cenderung kritis dan terkadang sulit menerima hal baru. Dengan demikian, mereka hanya fokus dan intens pada satu kondisi, sehingga terkadang kesimpulan yang dianggapnya benar ternyata masih keliru.

Kondisi-kondisi sebagaimana telah diuraikan di atas, ternyata berpengaruh secara signifikan terhadap hasil belajar qiro'ah (membaca) bahasa Arab perserta didik. Dengan kata lain, kondisi pembelajaran yang terjadi di dalam kelas dan perbedaan-perbedaan antara perserta didik yang divergen dan konvergen telah membuat hasil belajar qiro'ah (membaca) bahasa Arab perserta didik divergen lebih

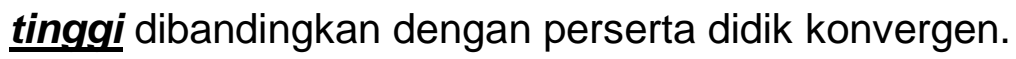

Hipotesis Ketiga. Terjadi pengaruh interaksi antara model pembelajaran kooperatif dengan gaya berpikir terhadap hasil belajar qiro'ah (membaca) 
bahasa Arab peserta didik. Hasil penelitian menunjukkan bahwa terdapat pengaruh interaksi antara model pembelajaran kooperatif ( $M M$ dan $N H T)$ dan gaya berpikir (divergen dan konvergen) terhadap hasil belajar qiro'ah membaca bahasa Arab. Hal ini dibuktikan oleh $F_{\text {hitung }}(A B)=23,48>F_{\text {tabel }}$ baik pada taraf signifikansi $\alpha=0,05$ maupun $\alpha=0,01$.

Berdasarkan pengamatan peneliti bahwa metode pembelajaran dan gaya berpikir merupakan perpaduan positif yang terjadi dalam kelas dalam pembelajaran qiroah, yang mana metode pembelajaran dikendalikan dan diatur oleh instruktur sedangkan gaya berpikir merupakan kecenderungan yang dimiliki peserta didik untuk mereka bagaimana caranya agar belajar menjadi menyenangkan.

Pada pembelajaran qiro'ah (membaca) tidak bisa dipandang sebelah mata karena dibutuhkan suatu ketrampilan tersendiri bagi pendidik agar peserta didik yang memiliki keragaman latar belakang wawasan dan pengetahuan yang beragam dapat memahami materi secara optimal. Seperti kita maklumi bahwa perbedaan individu adalah suatu keniscayaan yang alamiah, salah satunya adalah perbedaan gaya berpikir. Gaya berpikir adalah cara yang disukai individu dalam menggunakan kemampuan atau ketrampilan yang dimilikinya untuk mengatasi masalah yang dihadapinya. Di antara model pembelajaran yang tepat dengan kondisi ini adalah model pembelajaran kooperatif. Model pembelajaran kooperatif adalah model pembelajaran yang bertujuan untuk mengembangkan potensi akademik peserta didik melalui kerja kelompok, sehingga mereka bisa saling bantu-membantu memahami pelajaran. 
Dengan mengetahui perbedaan individu, maka kita dapat memberikan model pembelajaran yang berbeda pula agar peserta didik dapat menyerap materi secara optimal.

Berdasarkan uraian di atas, maka terbukti terdapat pengaruh interaksi antara model pembelajaran kooperatif dan gaya berpikir terhadap hasil belajar membaca bahasa Arab.

Hipotesis Keempat. Hasil belajar membaca bahasa Arab peserta didik yang ajarkan dengan model pembelajaran kooperatif teknik Mind Mapping lebih tinggi dari pada peserta didik yang diajarkan dengan model pembelajaran kooperatif teknik Teknik numbered Head Together (NHT) pada kelompok perserta didik yang memiliki kecenderungan berpikir konvergen. Hasil penelitian menunjukkan bahwa tidak terdapat perbedaan yang signifikan antara hasil belajar qiro'ah (membaca) bahasa Arab perserta didik yang belajar dengan model kooperatif $M M$ dengan perserta didik yang belajar dengan model kooperatif $N H T$ pada kelompok perserta didik konvergen. Hal ini dibuktikan melalui $\mathrm{Q}_{\text {hitung }}=2,16<\mathrm{Q}_{\text {tabel }}$ pada taraf signifikansi $\alpha=0,05$.

Model pembelajaran kooperatif $M M$ dan $N H T$ bagaimanapun merupakan dua model dari rumpun pembelajaran kooperatif yang sama-sama memiliki unsur: 1) Saling ketergantungan positif, 2) tanggung jawab perseorangan, 3) tatap muka, 4) komunikasi antar anggota, 5) evaluasi proses kelompok. Sedangkan yang membedakan $M M$ dan $N H T$ adalah pada 1) proses: proses pada $M M$ perserta didik 
membuat konstruksi bersama yang dilengkapi dengan mind mapping, sedangkan NHT hanya membuat konstruksi bersama. 2) konfirmasi: konfirmasi pada $M M$ konfirmasi peserta didik dilakukan bersama-sama, sedangkan NHT dilakukan secara bersama-sama dan individu.

Sebagaimana karakteristik individu dengan kecenderungan gaya berpikir konvergen yaitu logis dan konvensional, mereka lebih cenderung dan menyukai hafalan dan teksbook dalam menguasai materi, bagi mereka perbedaan pelaksaaan model pembelajaran kooperatif di dalam kelas tersebut nampaknya kurang begitu berkesan berbeda karena mereka hanya mengikuti arus pembelajaran yang ada pada teks saja tanpa elaborasi yang mendalam sehingga hasilnya pun tidak begitu mencolok.

Berdasarkan uraian di atas, maka disimpulkan bahwa tidak terdapat perbedaan yang signifikan antara hasil belajar qiro'ah (membaca) bahasa Arab perserta didik yang belajar dengan model pembelajaran kooperatif mind mapping dengan perserta didik yang belajar dengan model pembelajaran kooperatif numbered head together pada kelompok perserta didik konvergen.

Hipotesis Kelima. Hasil belajar membaca bahasa Arab peserta didik yang ajarkan dengan model pembelajaran kooperatif teknik Mind Mapping lebih tinggi dari pada peserta didik yang diajarkan dengan model pembelajaran kooperatif teknik Teknik numbered Head Together (NHT) pada kelompok perserta didik yang memiliki kecenderungan berpikir divergen. Hasil penelitian menunjukkan bahwa hasil belajar qiro'ah (membaca) bahasa Arab perserta didik yang 
belajar dengan model pembelajaran kooperatif MM lebih tingqi daibandingkan dengan perserta didik yang berlajar dengan model pembelajaran kooperatif $N H T$ pada kelompk perserta didik yang memiliki kecenderungan gaya berpikir divergen. Hal ini dibuktikan oleh $Q_{\text {hitung }}=7,95<Q_{\text {tabel }}$ baik pada taraf signifikansi $\alpha=0,05$ maupun $\alpha=0,01$.

Berdasarkan penelitian yang berlangsung pada kelas kooperatif $M M$ dan kelas NHT pada kelompok perserta didik divergen peneliti menemukan bahwa tampaknya jawabanya tidak begitu berbeda jauh dari jawaban untuk hipotesis pertama, yaitu: bahwa membaca merupakan aktifitas kognitif yang menuntut kerja otak secara optimal dalam memahami teks, selaras dengan aktifitas tersebut, caracara kerja mind mapping dan karakteristik gaya berpikir divergen tampaknya terjadi sinergisitas yang sangat baik dalam proses membaca. Sebagaimana cara kerja pada mind mapping yaitu membantu mengoptimalkan kerja otak secara maksimal dengan melibatkan otak kanan dan kiri secara sinergis ketika mengolah berbagai informasi dalam hal ini ketika mereka membaca lalu merangkum teks tersebut yang dituangkan ke dalam mind mapping, dan terlebih mind mapping ini dilakukan secara kooperatif. Dan juga karakteristik gaya berpikir divergen yakni mampu berpikir luwes dan kreatif, sebagaimana dimaklumi dalam membaca terlebih untuk tingkat pemula seringkali menemui kosa kata yang asing, permasalahan ini nampaknya mudah diatasi oleh mereka yang terus berusaha dan mencoba dengan berbagai cara, baik memahaminya memalui konteks, mencari turunan kata atau derivasinya, bertanya ke teman, dan lain-lain. 
Dengan demikian, berdasarkan uraian di atas, maka hasil belajar qiro'ah (membaca) bahasa Aab perserta didik yang belajar denga model pembelajaran kooperatif $M M$ lebih tingqi dibandingkan dengan perserta didik yang belajar dengan model kooperatif $N H T$ pada kelompok perserta didik berpikir divergen.

Berdasarkan hasil penelitian dan kesimpulan yang telah dikemukakan, maka penelitian berimplikasi terhadap upaya untuk meningkatkan hasil belajar qiro'ah (membaca) bahasa Arab melalui penerapan model pembelajaran kooperatif dan identifikasi gaya berpikir. Dengan kata lain, identifikasi gaya berpikir sedini mungkin dapat membantu menentukan model pembelajaran yang tepat yang pada akhirnya akan meningkatkan hasil belajar qiro'ah (membaca) bahasa Arab.

\section{Daftar Pustaka}

Abidin, Yunus. (2014). Desain Sisitem Pembelajaran dalam Konteks kurikulum 2013. Bandung: Refika Aditam,.

Bohlin, Lisa, Cheyl Cisero Durwin, dan Marla Reese Webe, Edpsych. (2012). New York: McGrowhill.

Brown, H. Douglas, Language Assesment Principles and Classroom Practices. Longman.

Hermawan, (2014). Asep, Metodologi Pembelajaran Bahasa Arab. Bandung: Remaja Rosdakarya.

Jihad, Asep dan Abdul Haris, (2012). Evaluasi Pembelajaran. Yogyakarta: Multi Pressindo.

John W. Santrock. (2006) Educational Psychology. New York: Mcgrowhill.

Jolliffe, Wendy. (2007). Cooperative Learning in the Class Putting it Into Practice. London: Paul Chapman Publishing.

Kagan, Spencer \& Miguel Kagan, (2009). Kagan Cooperative Learning. San Clemente: Kagan Publishing.

Khodijah, Nyayu. (2014). Psikologi Pendidikan. Depok: Raja Grafindo Persada. 
Lehay, Benjamin B. (2012). Psychology an Introduction. New York: Mcgrowhill. Lie, Anita. (2010). Cooperative Learning Mempraktikkan Cooperative Learning di Ruang-Ruang Kelas. Jakarta: Grasindo.

Marzano, Robert J. dan John S. Kendall. (2007) The New Taxonomy of Educational Objective. California: Corwin Press.

Nuttall, Christine (1989). Teaching Reading Skills in a Foreign Language. Oxford: Heinemann International.

Saefuddin, H. Asis dan Ika Berdiati, Pembelajaran Efektif. Bandung: Remaja Rosdakarya.

Daelami. (2016). Standarisasi Kurikulum Pendidikan Bahasa Arab Di Perguruan Tinggi Keagamaan Islam Negeri, Jurnal Pendidikan Bahasa Arab dan Kebahasaaraban, 3(1), 32-51.

Sternberg, Robert J., Thinking Styles. New York: Cambridge, 2009. , Nature Creativity: Creativity Journal, Vol. 18 (1).

Purwanto. (2011). Evaluasi Hasil Belajar. Yogyakarta: Pustaka Pelajar.

Rusman. (2013). Model-model Pembelajaran Mengembangkan Profesionalisme Guru. Jakarta: Rajawali Press.

Rissner, Criptoph, (2003). Seminarwork Mind Maps.

Sadia, I Wayan. (2014). Model-model Pembelajaran Sains Konstruktivistik.

Yohyakarta: Graha Ilmu.

Santrock, John W. .(2006). Educational Psychology. New York: Mcgrowhill.

Slavin, E. Robert. (2008). Psikologi Pendidikan Teori dan Praktik Edisi Kedelapan. Jakarta: PT.Indeks.

Sudjana, Nana, (2009). Penilaian Hasil Proses Belajar Mengajar. Bandung: Rosdakarya.

Wahyuni, Sri dan Abd. Syukur Ibrahim. (2012). Asesmen Pembelajaran Bahasa. Bandung: Refika Aditama.

Woolfolk, Anita, (2007). Educational Psychology. Boston: Pearson.

Zang, Li Fang, Robert J. Sternberg, dan Stephen Rayner. (2012). Handbook of International Intellectual Style. New York: Springer Publishing Company.

$$
\begin{aligned}
& \text { فواز بن فتح الله الراميني، الكثاف الأمين في معايير فنون اللغة العربية و طر ائق تدريسها المتمركزة على المتعلم } \\
& \text { عدنان يوسف العتوم و عبد الناصر ذياب الجراح، موفق بشارة. . (2007). مهارات التفكبير نماذج نظربية و تطبيقات } \\
& \text { عملية. عمان: دار المسيرة. } \\
& \text { حمد هداية الله زركثي. (1991). اللغة العربية في إندونبسية دراسة و تاريخيا. لاهوري باكستان: تسبس جامعة بنجاب. } \\
& \text { خالد بن خاطير العبيدي. (2012). مستقبل التبية العربية. المركز العربي التعليمي و التنمية. }
\end{aligned}
$$

